\title{
Influencia del desarrollo de la inteligencia emocional en el contexto turístico actual cubano
}

Influence of the development of emotional intelligence in the current Cuban tourism context

Yulima Daimet Valdés Bencomo. ${ }^{1}$, Cinthia Balcárcel Mara. ${ }^{2}$, Miguel Ángel Bulit Villafaña. ${ }^{3}$ \& Luis Efraín Velasteguí López. ${ }^{4}$

\begin{abstract}
.
DOI: https://doi.org/10.33262/concienciadigital.v4i2.1693

The following article seeks to demonstrate the importance of the development of Emotional Intelligence in workers in the touristic sector in Cuba. The ability to understand other people's emotions as well as our own, is tightly linked with professional and personal success. Nowadays its quite obvious that business excellency is based on the right on the management of human resources, therefore, Emotional Intelligence has become a subject of special interest for tourism workers. In order to fulfill the purpose of this article and get a broader vision of the term, the origin, evolution and basic principles of Emotional Intelligence are addressed. Its importance within work environment is exposed later on, and the benefits for the touristic sector are highlighted. Also, there's a summary of the negative effects Covid-19 pandemic has had for tourism enterprises and how Emotional Intelligence can help mitigate them. Finally, the most relevant conclusions of the investigations are exposed and explained.
\end{abstract}

Keywords: Emotional Intelligence, tourism sector and Covid-19

\footnotetext{
1 Universidad de la Habana. La Habana, Cuba. yulima40@ gmail.com, Orcid: 0000-0003-4477-166x

2 Universidad de la Habana. La Habana, Cuba. cinthiabm1508@gmail.com, Orcid: 0000-00030191-3250

3 Universidad de la Habana. La Habana, Cuba. miguelito42@gmail.com, Orcid: 0000-0003-0068-0053

${ }^{4}$ Ciencia Digital Editorial, Ecuador, luisefrainvelastegui@cienciadigital.org
} 


\section{Resumen.}

El presente trabajo persigue como objetivo de fundamentar la importancia del desarrollo de la Inteligencia Emocional en los trabajadores del sector turístico en Cuba. La capacidad de entender las emociones propias y ajenas guarda una estrecha relación con el éxito personal y profesional. En los últimos tiempos se ha convertido en un tema de especial interés para los profesionales del turismo, pues es evidente que la excelencia empresarial en la actualidad, se basa en la gestión de sus recursos humanos. Para cumplir con el propósito del artículo, se aborda sobre los inicios, evolución y principales definiciones de la Inteligencia Emocional, en aras de tener una visión más amplia del término. Posteriormente se expone su importancia dentro del ámbito laboral, resaltando los beneficios que aporta al sector turístico. Seguido de un resumen sobre algunos efectos negativos provocados por la crisis impuesta por el Covid-19 en las empresas turísticas y cómo la Inteligencia Emocional puede contrarrestarlos. Finalmente, se arriba a las conclusiones más relevantes sobre la temática abordada.

Palabras claves: Inteligencia Emocional, sector turístico y Covid-19

\section{Introducción}

Numerosos son los estudios publicados que demuestran la relación existente entre, coeficiente intelectual, inteligencia emocional, relaciones humanas y el éxito. Aunque en sus inicios, la Inteligencia Emocional no se definió como tal, siempre estuvo latente su importancia y es por ello que, en la actualidad, existe una literatura amplia sobre estudios sicológicos de la misma.

Sin embargo, en relación con el contexto cubano, las investigaciones sobre la Inteligencia Emocional en las empresas son escasas, no obstante, cabe resaltar que existe bibliografía con relación a dicha temática en Cuba, pero poseen un enfoque académico por lo general.

El presente trabajo pretende resaltar la importancia del desarrollo de la Inteligencia Emocional en los trabajadores del sector turístico en Cuba, pues, profundizando en el éxito profesional, los predictores no cognitivos han ido cobrando fuerza en la psicología industrial para su aplicación en procesos de selección debido a los problemas de las pruebas cognitivas para predecir el rendimiento en el trabajo (Schmidt y Hunter, 1998).

Contar con un personal que reúna casi todos los componentes de la misma, constituye una ventaja competitiva para las entidades, sobre todo para aquellas que se encuentran en una posición desfavorable en el mercado, para así, aumentar la satisfacción del cliente y, por consiguiente, el índice de repitencia, de forma tal que la IE supla las carencias que pueda presentar un servicio, o, por el contrario, que potencie sus fortalezas.

Para cumplir con el objetivo antes mencionado, se emplearon varios métodos teóricos como el analítico y sintético, mediante el cual se llevó a cabo el procesamiento de la 
información obtenida de la revisión bibliográfica, que permitió el análisis teórico existente sobre la Inteligencia Emocional a nivel mundial y determinar su potencial para las empresas turísticas, llevando un análisis de lo general a lo particular. El método histórico-lógico se utilizó para profundizar en los criterios de los diferentes autores sobre la Inteligencia Emocional y su evolución histórica y, por último, gran parte de la literatura consultada fue obtenida de la búsqueda referencial en Internet, en particular, los estudios recientes sobre la importancia de la

Inteligencia Emocional tras la crisis provocada por el COVID-19.

A partir de la década del $80^{\prime}$ se destacan múltiples teorías psicológicas que han revolucionado el concepto de inteligencia, en aras de lograr una visión más acertada del mismo, lo cual ha llevado a la introducción de nuevos términos, siendo la Inteligencia Emocional, uno de los más significativos.

Uno de los autores más influyentes en cuanto a la Inteligencia Emocional es el psicólogo americano Daniel Goleman, sin embargo, durante el siglo XX algunos autores se adentraron o hicieron referencia a ello, como es el caso del psicólogo Edward Thorndike, quien en 1920 define la Inteligencia Social como "la capacidad de entender y manejar a los hombres y mujeres, niños y niñas para actuar sabiamente en las relaciones humanas", dejando entrever que la Inteligencia Social es precursora de la Emocional.

Años más tarde, en 1940, David Wechsler, psicólogo reconocido por su test de inteligencia, plantea que sobre el comportamiento inteligente actúan factores no intelectivos, y que, por tanto, mientras no se puedan definir correctamente dichos factores, no estarán completos los test de inteligencia.

En teoría, el término "inteligencia emocional" tiene su primer uso en textos de Beldoch (1964) y B. Leuner (1966), el cual publicó un artículo en alemán donde se refiere a cómo las mujeres rechazan un rol social debido a su baja inteligencia emocional. Aunque generalmente se le atribuye a Wayne Payne en 1986 en su tesis doctoral, titulada "Un estudio de las emociones: el desarrollo de la inteligencia emocional", planteando el problema entre la razón y las emociones, así como la necesidad de incorporar a las escuelas la integración de la emoción con la inteligencia; es por ello que se puede afirmar que, desde sus inicios, la inteligencia emocional tenía una vocación educativa.

Gardner (1983), en su libro "Frames of mind. The theory of multiple intelligences", considera que la inteligencia es la capacidad para resolver problemas o elaborar productos que puedan ser valorados en una determinada cultura; es un potencial que cada ser humano posee ya sea en menor o mayor medida y añade que todos los hombres son inteligentes de alguna forma, dado que poseen alguna habilidad predominante. En dicha obra hace uso del término "inteligencia personal" la cual está compuesta por la inteligencia intrapersonal, referida al conocimiento de los aspectos internos de una persona, y por la inteligencia interpersonal, basada en la capacidad básica para notar las 
distinciones entre otros, en particular, el contraste en sus estados de ánimo, temperamentos, motivaciones e intenciones (Gardner, 1993).

En 1990 los autores Peter Salovey y John D. Mayer desarrollan en sus trabajos seminales, una teoría sobre la Inteligencia Emocional y algunos criterios para su medición. Plantean que es un subconjunto de la Inteligencia Social que implica la capacidad de controlar los sentimientos y emociones tanto propias como ajenas, para discriminar entre ellos y utilizar esta información para guiar el pensamiento y la conducta propia.

Goleman (1995), publica el best seller que lo catapulta a la fama, cuyo tema principal nace de la unión de las inteligencias intrapersonal e interpersonal antes mencionadas; fue así como la Inteligencia Emocional, se convierte en un término muy notorio cuya popularidad asciende rápidamente en la época. La define como "la capacidad de reconocer nuestros propios sentimientos y los de los demás, de motivar(nos) y de manejar adecuadamente las relaciones".

Pese a que Salovey y Mayer no logran popularizar el concepto en su momento, la definición que proponen sobre la IE no está muy lejos de lo planteado por Goleman, el cual reconoce que se basó en el trabajo de dichos autores, quienes tras revisar el concepto que plantean, proponen una definición más completa, donde expresan que la Inteligencia Emocional es "la capacidad de percibir con exactitud, valorar y expresar emociones; la capacidad de encontrar y/o generar sentimientos cuando éstos faciliten el pensamiento y la capacidad de comprender y regular las emociones para promover el crecimiento emocional e intelectual". (Mayer\&Salovey,1997, p.5).

Tanto las dos versiones de Salovey y Mayer, como la definición de Goleman son complementarias y el gran auge de este concepto, se debe a que tanto el conocimiento como las emociones están estrechamente relacionados y son responsables del éxito en diferentes aspectos de la vida.

Para Daniel Goleman, dentro del término IE existen dos grandes tipos que, a su vez, estos están compuestos por determinadas competencias. Primeramente, se encuentra la Inteligencia Personal que comprende tres componentes. Uno de ellos es la conciencia en uno mismo, se refiere a percatarse de los estados de ánimos propios, lo cual permite conocer la influencia de cada uno de ellos tanto en el trabajo como en el resto de las personas.

Otro factor muy importante en la Inteligencia Personal es la autorregulación, pues gracias a esta habilidad el individuo controla sus emociones e impulsos para adaptarlos a un objetivo, es capaz de responsabilizarse por sus actos y de pensar antes de cometer una acción, para así, enfrentar correctamente los contratiempos.

Por último, está presente la habilidad de automotivarse, de ver ante el fracaso, una oportunidad para mejorar y un compromiso real de anteponerse a las adversidades. Las 
personas con dicha habilidad, atribuyen su éxito o su fracaso a sus propias acciones, en lugar de circunstancias o personas ajenas.

El otro tipo de IE recibe el nombre de Inteligencia Interpersonal; una persona emocionalmente inteligente debe tener la habilidad de reconocer emociones ajenas, debe ser capaz de determinar sus necesidades y responder de forma adecuada a sus reacciones emocionales. La empatía logra que el individuo considere los sentimientos de los demás y ante situaciones problemáticas, actúa de forma correcta, entendiendo sus puntos de vista.

Además, otro componente fundamental es la habilidad social, el arte de relacionarse con el resto, pues una vez reconocidas sus emociones, llega el momento de solucionar los conflictos, de negociar, de darle tratamiento a los problemas; consiste en saber persuadir y lograr influenciar a la otra parte.

La inteligencia emocional empieza con la conciencia de uno mismo y también con la conciencia social, es decir, al ser capaz de reconocer las emociones y su impacto en todo lo que rodea. Supone entender que gran parte del comportamiento y de las decisiones están basados en las emociones. El grado de dominio que alcance una persona sobre estas habilidades resulta decisivo para determinar el motivo por el cual ciertos individuos prosperan en la vida mientras que otros, con un nivel intelectual similar, no lo consiguen.

\section{Desarrollo}

La Inteligencia Emocional se convierte en una herramienta valiosa en el ámbito empresarial que permite comprender la productividad laboral del individuo, los requisitos del líder, el éxito e incluso, la prevención de desastres dentro de la organización. Resulta tan evidente el interés por la IE en los últimos tiempos debido a que se reconoce el valor innegable de las emociones en el mundo empresarial y los beneficios que aporta en el rendimiento laboral, entre los que se destaca:

- Mejoramiento del autoconocimiento y la toma de decisiones

- Manejo adecuado del estrés y correcto desempeño del individuo al trabajar bajo presión

- Potenciación de la capacidad de liderazgo y de influencia sobre un colectivo

- Aumento de la efíciencia y eficacia del empleado y del equipo de trabajo

- Mejoramiento de la comunicación dentro de la empresa y de las relaciones interpersonales

- Contribución al desarrollo personal

- Bienestar psicológico

- Aumento considerable de la motivación y, por consiguiente, de la posibilidad de alcanzar las metas propuestas con mayor seguridad

- Reducción de la ansiedad 
Para comprender con mayor exactitud la fundamentación teórica, se muestra un cuadro resumen adaptado referente a los indicadores de la Inteligencia Emocional y a los aspectos principales de cada uno (Fienco, Itúrburo, 2012)

\begin{tabular}{|c|c|}
\hline Indicadores & Aspectos esenciales \\
\hline $\begin{array}{l}\text { Auto-regulación: } \\
\text { capacidad de manejar y } \\
\text { controlar el propio } \\
\text { estado emocional. }\end{array}$ & $\begin{array}{l}\text { Posponer juicios; refrenar impulsos. } \\
\text { Dejar el problema. Expresarse de manera asertiva, no } \\
\text { agresiva. } \\
\text { Ser flexible. } \\
\text { Manejar la comunicación no verbal. }\end{array}$ \\
\hline $\begin{array}{l}\text { Autoconciencia: } \\
\text { conocerse a sí mismo y } \\
\text { entender las emociones }\end{array}$ & $\begin{array}{l}\text { Respetarse. } \\
\text { Ser positivo. } \\
\text { Ser fiel a sí mismo. } \\
\text { Dar un descanso a la lógica y a la racionalidad. } \\
\text { Escuchar a los demás. } \\
\text { Entender el impacto en los demás. }\end{array}$ \\
\hline $\begin{array}{l}\text { Motivación: } \\
\text { canalización de las } \\
\text { emociones para } \\
\text { alcanzar las metas. } \\
\text { Empatía: } \\
\text { reconocimiento y } \\
\text { sensibilización de las } \\
\text { emociones ajenas }\end{array}$ & $\begin{array}{l}\text { Luchar por mejorar y alcanzar estándares altos. } \\
\text { Comprometerse a alcanzar sus metas. Tomar la iniciativa y } \\
\text { aprovechar las oportunidades. } \\
\text { Ser optimista incluso en presencia de la adversidad. } \\
\text { Ser sensible hacia otras personas y comprenderlas. } \\
\text { Convertir las necesidades e intereses de otros en puntos de } \\
\text { referencia. } \\
\text { Fomentar el desarrollo de otras personas. } \\
\text { Estar en sintonía con lo social y lo político }\end{array}$ \\
\hline $\begin{array}{l}\text { Habilidades sociales: } \\
\text { relación con los demás } \\
\text { e influencia sobre ellos }\end{array}$ & $\begin{array}{l}\text { Desarrollar y mantener relaciones interpersonales } \\
\text { Comunicarse con los demás. } \\
\text { Trabajar con otras personas. }\end{array}$ \\
\hline
\end{tabular}

Tabla 1.

Fuente: Elaboración propia

Una vez planteado esto, queda en evidencia que, para los trabajadores del turismo, la Inteligencia Emocional es un pilar fundamental para su desempeño laboral. El sector turístico en los últimos años opera en un campo cuya competencia se ha intensificado, cada vez existen menos barreras de entradas para nuevos productos $\mathrm{y}$, además, las empresas y destinos turísticos se esfuerzan por adaptarse a las nuevas necesidades de sus clientes. Sin embargo, ofrecer productos novedosos no es suficiente, pues el turista viaja en busca de emociones para su enriquecimiento personal y satisfacer sus exigencias constituye una estrategia muy importante.

Es un reto constante para las empresas turísticas, mejorar cada día la calidad de los servicios prestados para resultar atractivos ante el mercado, debido a que, cada vez se dificulta más lograr un mayor número de clientes, y es necesario, además, fomentar su fidelización. Es por ello que las empresas necesitan enfatizar en la manera en la que los profesionales del sector interactúan con los clientes, por tanto, su preparación y formación práctica, lejos de ser una ventaja, se convierte en una exigencia competitiva. 
Sin embargo, es un hecho indiscutible que, en la actualidad, la formación y la experiencia no lo son todo, sino la manera en que las personas se relacionan con los demás y la inteligencia emocional en las acciones laborales son de importancia para el logro del éxito profesional. La capacidad de detectar las necesidades propias y ajenas resulta ventajosa para generar el crecimiento personal, siendo el equilibrio de las emociones quien puede llegar a determinar las respuestas, la funcionalidad y la interacción adecuada en el mundo laboral.

Se debe tomar en cuenta que el coeficiente intelectual, en muchas ocasiones es opacado por la inteligencia emocional. El hecho de que un trabajador cuente con coeficiente intelectual alto, no asegura que sea eficiente, es posible que obtenga mejores resultados dentro de una organización, alguien con grandes facilidades para relacionarse y trabajar en equipo que una persona con un razonamiento matemático excelente.

En los próximos años, aquellas empresas turísticas que logren fomentar mejor la colaboración entre sus trabajadores serán las más competitivas en el mercado. Además, las habilidades de la inteligencia emocional no sólo resultan indispensables para sobrevivir, sino que permiten disfrutar del trabajo en un entorno laboral en continuo proceso de cambio y con demandas de mayor exigencia.

La interacción entre los trabajadores y los clientes en el turismo, requiere de comportamientos profesionales muy determinados en el momento de realizar sus tareas, las cuales exigen expresar emociones positivas tales como la empatía, la tolerancia, educación y una gran sensibilidad para así, identificar y a su vez tratar correctamente las emociones del cliente. Si bien es importante que las empresas se preocupen por la satisfacción laboral de los empleados en todas las esferas, en el sector turístico lo es aún más, debido al contacto intensivo al cual se someten los trabajadores.

La inteligencia emocional dentro de la empresa debe comenzar por el interés propio de desarrollo personal, donde el individuo intenta conocerse a sí mismo y buscar una mejora continua, para así, hacer frente a los demás y a la empresa.

Fernández (2011), menciona que para que una organización desempeñe un trabajo con niveles altos de calidad y así, incrementar la productividad, resulta necesario no sólo aprender a administrar personas, sino mentes. El personal debe ser conducido a seguir las normas de la empresa, incluyendo la seguridad y salud laboral, motivarlos y enseñarles a realizar actividades de manera óptima.

No resulta del todo factible invertir solo en nuevas tecnologías, renovar la instalación o mejorar las técnicas de gestión por mencionar algunos ejemplos, si luego no se cuenta con un personal realmente inteligente emocionalmente, especializado y sobretodo motivado, que sea capaz de prestar el servicio adecuado a través de las expectativas de los clientes. 
Los empleados deben desarrollar habilidades de inteligencia emocional para adaptarse a funciones más relacionadas con el trato personal y del cliente, así como a tareas donde las competencias emocionales, como la empatía o el trabajo en equipo, resulten esenciales.

La inteligencia emocional cuenta con una serie de características que aportan estabilidad a las personas en cuanto al manejo de sus emociones, contribuyendo a la formación de personas profesionales y responsables por el bienestar de todo su medio empresarial. Los atributos de naturaleza personal como son el entusiasmo, la integridad, la tenacidad, la empatía, la humildad y la confianza, se complementan con el nivel de inteligencia emocional y la vía en la que la persona los equilibra de forma óptima, logrando así, un mayor rendimiento en su ámbito laboral.

El turismo, por su parte, demanda interacciones habitualmente breves, pautadas y ligeramente intensas, es ahí donde los empleados deben expresar las emociones adecuadas, lo cual requiere un importante esfuerzo. Es por ello, que se considera fundamental que las empresas dediquen el tiempo y recursos en formar a los empleados en caso de que estos presenten carencias en aspectos del trabajo emocional.

En una de las secciones del libro de Daniel Goleman (1999) titulado "La Inteligencia Emocional en la Empresa" se muestran resultados de distintas encuestas de evaluación realizadas en empresas y se evidencia el desaprovechamiento de las posibilidades de reflexión con relación a lo que hace efectiva a una entidad, así como las formas de diagnosticar las insuficiencias en el desempeño.

Se muestran deficiencias en cuanto a la comprensión de los sentimientos y perspectivas ajenas, en la capacidad de persuasión, la creación de lazos personales y en la toma de una conciencia política, es decir, en comprender el estado cambiante de las tendencias en la economía, la política y en el ámbito social. Los fallos en sentido general, se concentran en el autoconocimiento emocional, la adaptabilidad ante ciertos desafíos y obstáculos, saber desempeñarse correctamente bajo situaciones de presión y no caer en estado de alarma, ser optimistas y flexibles ante los problemas.

Estos indicadores son determinantes en el correcto desempeño del individuo dentro de una empresa. Las personas con un grado alto de optimismo tienden a ver el lado positivo de las situaciones y expresan satisfacción con su vida en general. Es una de las facetas de la inteligencia emocional que domina, por lo tanto, las relaciones entre las personas y sirve para aumentar la confianza en el ámbito laboral.

La flexibilidad se refiere a la sensibilidad que presenta el individuo ante el cambio. Las personas flexibles corren el riesgo de ser persuadidos con facilidad, pero saben responder 
positivamente a los cambios. También poseen características importantes como la autorregulación que les permite actuar bien ante emociones negativas.

Es un error no tomar en cuenta los estados emocionales de los trabajadores, pues ignorar cualquier categoría de datos significativos es limitar el conocimiento y la reacción, lo que demuestra el desconocimiento de las empresas con relación a este tema y cómo son incapaces de comprender los múltiples beneficios que puede reportarle a su organización.

Las realidades emocionales son marginadas en muchas ocasiones y no se tienen presente dentro de las reglas básicas, por consiguiente, se desarrollan una serie de problemas tales como:

- la dificultad para manejar la creatividad

- la incapacidad de motivar

- un liderazgo escaso de energías e impulso

- la falta de espíritu de equipo

- toma de decisiones erróneas

- actitudes pocas espontáneas

En las evaluaciones de desempeño de todas las entidades turísticas se debe incluir la inteligencia emocional como una de las competencias claves a evaluar y de esta forma, identificar a los empleados con un alto potencial para liderar equipos y tomar decisiones inteligentes que contribuyan al incremento de la competitividad y la productividad de la empresa.

Es un hecho habitual que las empresas se basen únicamente en las habilidades técnicas del individuo a la hora de contratarlo, obviando que las personas emocionalmente inteligentes se adaptan con mayor facilidad a entornos diferentes y poseen una mejor capacidad para establecer relaciones con sus colegas y clientes. Por lo general, si un individuo no presenta un nivel adecuado de inteligencia emocional, pese a sus altas habilidades numéricas y técnicas, puede presentar dificultades a la hora de enfrentarse a determinadas situaciones propias del día a día de una organización.

Es por ello que muchos empleados no cubren las expectativas en sus primeros meses y fracasan, siendo la falta de inteligencia emocional, una de las principales causas, por tanto, el proceso de contratación del personal se torna cada vez más importante de lo normal.

Por otro lado, a menudo se suele pensar que los temas psicológicos no repercuten en la productividad, clima y cultura organizacional, no obstante, la Organización Internacional de Trabajo ha indicado que se estima que en el mundo existan más de 260 millones de personas con depresión, siendo esta una de las principales causas de discapacidad en el ámbito laboral y según un reciente estudio dirigido por la Organización Mundial de la 
Salud, los trastornos por depresión y ansiedad cuestan a la economía mundial 1 billón de dólares anual en pérdida de productividad.

En diciembre de 2019, en Wuhan, provincia de Hubei, China, se informaron casos de neumonía potencialmente mortal y para enero de 2020, la enfermedad conocida como COVID-19 había llegado a 19 países, con la desorbitante cifra de 11.791 casos confirmados y 213 muertes. Es evidente que el virus ha experimentado un fenómeno de rápida propagación, lo cual ha conllevado a colapsar los sistemas sanitarios a nivel mundial y a una inadecuada capacidad de respuesta de los servicios de urgencia ante la alta demanda en tan poco tiempo; siendo esto uno de los aspectos más graves independientemente de los síntomas propios del virus.

Ha sido el comportamiento de las personas y su baja percepción de riesgo quien, unido a los factores biológicos de la enfermedad y la ausencia de una vacuna contra el virus, ha colapsado sanitaria, política y económicamente al mundo. La crisis provocada por esta infección respiratoria exige de un gran manejo de la ansiedad y de los síntomas psicológicos, así como el desarrollo de la tolerancia ante la inseguridad; pues ha quedado demostrado que, aunque el factor biológico es esencial, han sido los factores psicológicos y sociales quienes lo han transformado en un desastre mundial.

El turismo, tercer sector más importante de la economía mundial en materia de exportaciones, se convierte en una de las esferas más dañadas. Tras el cierre repentino de los viajes y el comercio mundial, provocado por una crisis sin precedentes en tamaño y amplitud, donde todas las partes de su cadena de valor se encuentran gravemente afectadas, se abre una nueva etapa en el sector del turismo, que exige un personal inteligente emocionalmente, capaz de gestionar la "nueva normalidad", de ahí la necesidad de transmitirle a los trabajadores, el arte de entender las emociones.

La reapertura paulatina de los viajes, la comunicación limitada y, por supuesto, la escasa confianza del turista, unido a la incertidumbre sobre el desarrollo de la enfermedad y el impacto negativo sobre la economía, implantan nuevos desafíos al sector turístico. La crisis ofrece una oportunidad de reinventarse, brindándole un desmedido protagonismo al bienestar del trabajador y del consumidor, no obstante, el turismo siempre ha demostrado una gran capacidad de resiliencia e innovación, fomentada por el aumento de la competencia.

Es evidente que las personas emocionalmente inteligentes son capaces de adaptarse con mayor facilidad a los cambios impuestos por la sociedad y a su vez, contribuyen a aminorar las inseguridades y preocupaciones del resto. Es por ello, que ante situaciones desfavorables como la que ha impuesto la pandemia del COVID-19, la IE desempeña un papel de suma importancia. 
La sociedad, sometida a una fuerte presión económica, social y laboral, enfrenta el desempleo o la relocalización de los trabajadores del sector estatal a actividades vinculadas al turismo o a la exportación de bienes, pero de menor remuneración, a la reducción de jornadas laborales y por tanto de los ingresos familiares, la aplicación de tele-trabajo: una modalidad refrendada en el Código del Trabajo cubano e impulsada por el país desde finales del 2019, a la reducción de las remesas, y todo unido a la incertidumbre del aislamiento social y la zozobra emocional. Tras más de un año de pandemia, el mundo comienza a vivir una nueva normalidad, donde la presión gestada se devolverá hacia la sociedad y las empresas.

Por tanto, la salud mental de los trabajadores debe ser en la actualidad, una prioridad para las empresas, y para ello se deben crear una serie de procesos que prevengan los desequilibrios emocionales de sus colaboradores y fortalezcan a las organizaciones para que las repercusiones resulten manejables en ambientes positivos.

Sin embargo, no todo resulta negativo, la crisis mundial ocasionada por el Coronavirus, ha evidenciado la resiliencia del ser humano, es decir, la capacidad de ajuste personal y social a pesar de vivir en un contexto desfavorable y de haber tenido experiencias traumáticas o situaciones de estrés es lo que define a la personalidad resiliente. Ese ajuste psicológico implica la capacidad de resistir a las adversidades, el control sobre el curso de la propia vida, el optimismo y una visión positiva de la existencia (Uriarte, 2005, pág. 63). Al establecer una comparación entre la IE y la capacidad de resiliencia, se evidencia la relación entre ellas y cómo ambas se asocian a perfiles de temperamento y rasgos de carácter como la autonomía, el control propio de las emociones y la actitud social positiva.

Siendo esto, lo que se requiere en las entidades turísticas, individuos "resilientes" que posean un alto nivel de competencia en distintas áreas, que mantengan un nivel subjetivo de bienestar psicológico, así como la capacidad de tener metas de realización personal y social, todo ello a pesar de los inevitables problemas y dificultades que enfrente en su puesto de trabajo.

\section{Conclusiones}

- Lograr un alto nivel de inteligencia emocional asegura un manejo integral del individuo, fomentando la buena administración e interrelación con su entorno.

- Para las organizaciones turísticas resulta imprescindible contratar y/o formar a su personal tomando en cuenta los indicadores de la inteligencia emocional en combinación con el resto de las aptitudes técnicas o experiencia laboral que requieren 


\section{Referencias bibliográficas}

Alzina, R. B. (2007). Psicopedagogía de las emociones. Madrid: Síntesis S.A.

Arciniega, J. U. (2005). La resiliencia. Una nueva perspectiva en psicopatología del desarrollo . Revista de Psicodidáctica, 10(2), 61-79.

Bertrand. (2016). Psicología y Mente.

Camejo, M. L. (10 de junio de 2015). Inteligencia y Competencias emocionales, su rol en el entorno laboral. Caso de Servicios turísticos en Cuba.

Cortés, A. G. (2014). EL TRABAJO EMOCIONAL Y SUS IMPLICACIONES EN EL SECTOR TURÍSTICO . Zaragoza.

Corzo, M. C. (2015). Comunicación en el ámbito empresarial del sector turístico cubano.

Danvila del Valle, I., \& Sastre Castillo, M. Á. (2010). Inteligencia Emocional: una revisión del concepto y líneas de investigación. Cuadernos de Estudios Empresariales, 20, 107-126.

empleostest.com. (s.f.). Obtenido de Inteligencia emocional en la empresa.

Escuela de Organización Industrial. (s.f.). Obtenido de Inteligencia Emocional en la Empresa: http://www.eoi.es

Fernández, R. (2011). La productividad y el riesgo psicosocial derivado de la organización del trabajo. España: Club Universitario.

Fienco Valencia, G., \& Itúrburo Salazar, J. (2012). La inteligencia emocional en el éxito empresarial.

García, M. F. (2015). Indicadores de inteligencia emocional percibidos de los colaboradores de una empresa de construcción en Guatemala. Tesis de grado, Universidad Rafael Landívar, Facultad de Humanidades, Guatemala.

Gardner, H. (1983). Frames of Mind: The Theory of Multiple Intelligences. New York: Basic Books.

Gardner, H. (1993). Multiple intelligences: The theory in practice. New York: Basic Books.

Goleman, D. (1995). Emotional Intelligence. New York: Bantam Books.

González, J. A. (junio de 2012). TURyDES. Obtenido de FORMANDO A LOS LÍDERES DE EMPRESAS TURÍSTICAS EN LA UNIVERSIDAD: http://www.eumed.net

Herrera, J. (s.f.). Inteligencia Emocional. Obtenido de http://www.monografías.com

López Boudeti, R., \& Martínez Vázquez, A. M. (mayo - agosto de 2014). Inteligencia Emocional y "la ventana del líder" en los directivos turísticos. La Habana, Cuba: Instituto Superior Politécnico José Antonio Echeverría, Cujae. Facultad de Ingeniería Industrial. 
M., S. E. (2016). La inteligencia emocional en los empleados que prestan servicios a los usuarios del Hospital Germán Vélez Gutiérrez del municipio Betulia-Antioquia. Facultad de Ciencias Sociales y Educación Programa de Psicología.

Méndez, P. J. (22 de abril de 2020). Problemas psicológicos y su afectación a las empresas tras el Covid-19. Obtenido de http://www.larepublica.net

Organización de Naciones Unidas. (2020). Informe de políticas: La Covid-19 y la transformación del turismo.

Pérez, I. A. (2014). Inteligencia Emocional y Productividad laboral (Estudio realizado con el personal de salud del Centro de Diagnóstico por imágenes) . Universidad Rafael Landívar, Facultad de Humanidades, Quetzaltenango.

Rodríguez, J. L., \& Odriozola, S. (2020). Impactos Económicos y Sociales de la COVID 19 en Cuba: Opciones de políticas. Oficina Coordinadora Residente y las agencias del Sistema de Naciones Unidas en Cuba.

Rodríguez, J. M. (2017). EL TRABAJO EMOCIONAL EN EL SECTOR TURÍSTICO. OBSTÁCULOS Y FACILITADORES EMPRESARIALES Y SUS CONSECUENCIAS PARA LOS TRABAJADORES. Tesis doctoral, Universitat de Girona, Girona.

Salovey, P., \& Mayer, J. D. (1997). What is emotional intelligence?. New York: Basic Books.

Schmidt, F. L., \& Hunter, J. E. (1998). The validity and utility of selection methods in personnel psychology: Practical and theoretical implications of 85 years of research findings. Psychological Bulletin.

Soriano Márquez, A. d., \& Díaz Cerón, A. M. (2019). La inteligencia emocional como factor importante en el liderazgo. Veracruz: Instituto de Investigaciones y Estudios Superiores de las Ciencias Administrativas de la Universidad Veracruzana.

Trujillo, M. A. (s.f.). LA RESILIENCIA EN LA PSICOLOGÍA SOCIAL. Facultad de Estudios Superiores IZTACAL.

Urzúa, A., Polanco Carrasco, R., Caqueo Urízar, A., \& Vera Villarroel, P. (2020). La Psicología en la prevención y manejo del COVID-19. Aportes desde la evidencia inicial. Chile.

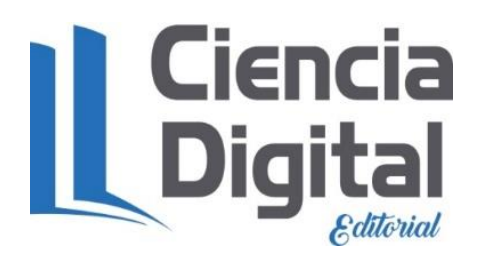




\section{PARA CITAR EL ARTÍCULO INDEXADO.}

Valdés Bencomo, Y. D., Balcárcel Mara, C., Bulit Villafaña, M. Ángel, \& Velasteguí López, L. E. (2021). Influencia del desarrollo de la inteligencia emocional en el contexto $\begin{array}{llll}\text { turístico actual cubano. } & \text { ConcienciaDigital, 4(2), 292-305. }\end{array}$ https://doi.org/10.33262/concienciadigital.v4i2.1693

\section{LCiencia}

El artículo que se publica es de exclusiva responsabilidad de los autores y no necesariamente reflejan el pensamiento de la Revista Conciencia Digital.

El artículo queda en propiedad de la revista y, por tanto, su publicación parcial y/o total en otro medio tiene que ser autorizado por el director de la Revista Conciencia Digital.

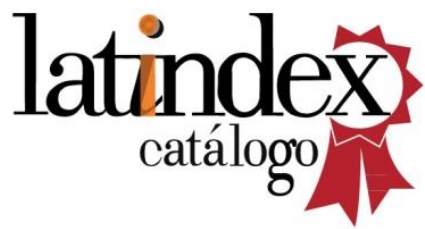

